\title{
ИСТОРИЯ ОТНОШЕНИЙ КНР И ИНДИИ В СФЕРЕ КУЛЬТУРНОГО СОТРУДНИЧЕСТВА В НАЧАЛЕ ХХІ В.
}

\section{HISTORY OF RELATIONS BETWEEN CHINA AND INDIA IN THE FIELD OF CULTURAL COOPERATION AT THE BEGINNING OF THE XXI CENTURY}

Gao Ven'czin

Summary: The article is devoted to the relations of the People's Republic of China and India in the field of cultural cooperation at the beginning of the XXI century. China and India are partners in both the BRICS and the Belt and Road initiative. The article examines the history of relations and problems existing between the two countries. The problems in the international cooperation between India and China are shown through the prism of the foreign policy relations of these countries. The partnership between India and China is quite complex. There is also a lack of interaction between the two countries in the field of cultural and tourist contacts, as well as educational student exchanges.

Keywords: China, India, culture, foreign policy, "One Belt, One Road", Asia.
$\mathrm{H}$ есмотря на то, что Китай и Индия имеют общую границу, история их взаимоотношений носит непростой характер. Наблюдается рост торгового оборота между странами. Растут китайские инвестиции в экономику Индии. Набирает обороты сотрудничество Китая и Индии на международной экономической арене БРИКС, ШОС и стратегического треугольника «РоссияИндия-Китай». Объем торгового оборота с Китаем занимает первое место в общем объеме внешней торговли Индии. Эти страны совместно решают вопросы, посвященные преодолению мирового финансового кризиса, проблемам изменения климата, борьбе с терроризмом, энергетической и продовольственной безопасности.

Несмотря на то, что в Индии не предусмотрены основные транспортные маршруты Нового Шелкового пути, предполагается строительство ответвлений от железнодорожных трансконтинентальных линий на ее территорию. Это связано с тем, что вдоль побережья Индии проходит маршрут Морского Шелкового пути [3].

Тем не менее, современные китайско-индийские отношения далеки от идеала, многие проблемы попрежнему остаются не решены, прежде всего, это касается военной и политической сфер. Правительство Индии пристально следит за укреплением и модернизацией вооружений армии Китая. Беспокоит его и усиление китайских позиций в Индийском океане. В Китае же
Гао Вэньцзин

Аспирант, Санкт-Петербургский Государственный Университет gaowenjing777@hotmail.com

Аннотация: Статья посвящена отношениям Китайской Народной Республики и Индии в сфере культурного сотрудничества в начале XXI в. Китай и Индия являются партнерами как по БРИКС, так и по проекту «Один пояс, один путь». Рассматривается история взаимоотношений и проблемы, существующие между двумя странами. Показаны проблемы в международном сотрудничестве Индии и Китая через призму внешнеполитических отношений этих стран. Партнерские отношения Индии и Китая носят довольно сложный характер. Между странами складывается и недостаточное взаимодействие в области культурных и туристических контактов, а также образовательных студенческих обменов.

Ключевые слова: Китай, Индия, культура, внешняя политика, «Один пояс, один путь», Азия.

проявляют беспокойство по поводу военной коалиции Индии со странами, стремящимися создать в Азии геополитический противовес Китаю.

Чтобы понять, почему возникли сложности в отношениях между двумя странами, нужно провести анализ временных изменений этих отношений. Выявить основные и трудно разрешимые проблемы, сложившиеся между государствами. Эти проблемы осложняют политические, экономические, военные и публичные контакты между двумя странами. Проблемы между Индией и Китаем возникают и при реализации долгосрочной политики и инвестиционной программы «Один пояс - один путь». Поэтому и публичная дипломатия Китая в отношении Индии носит не последовательный и запутанный характер [11].

Охлаждение в отношениях Индии и Китая наметились с 1962 года после возникновения высокогорного пограничного конфликта. В центре разногласий политического и территориального характера между двумя странами до сих пор находится «линия Макмагона», неточная граница, проведенная в 1914 г. властями Британской Индии и правительства Тибета. Ее длина около 900 км, она проходит от Бутана на западе до пункта, находящегося примерно в 260 км южнее поворота реки Брахмапутра на востоке. Большая часть границы проходит вдоль Гималаев. Китайское правительство не признает эту границу, и в приграничном конфликте 1962 года 
индийские войска понесли поражение. Индийцы еще помнят об этом поражении. Точная граница в этом регионе между странами до сих пор не определена. Поэтому данная ситуация остается источником возможного военного конфликта между двумя ядерными державами. Обе армии по-прежнему находятся в боевой готовности, и продолжают строительство приграничных военных сооружений и коммуникаций [5].

Экономические реформы, проведенные китайским правительством, позволили стране достичь больших успехов в экономике, совершить ряд научно-технологических прорывов, осуществить полномасштабную реорганизацию вооруженных сил. Модернизация в последнее время ведется усиленными темпами. Это, в свою очередь, вызывает опасения у индийского правительства. Учитывая тот факт, что Пекин стремится показать военную и экономическую мощь и никогда не говорил об отказе использования своей армии в международных конфликтах, существует вероятность использования вооруженных сил Китая при решении спорных вопросов.

Руководство Индии с опасением относится к модернизации китайской армии. Некоторые индийские политики полагают, противостояние с Китаем может стать более актуальным, чем с Пакистаном. Однако сам Китай не считает, что Индия является его противником и готов улучшить отношения с ней, в том числе в рамках БРИКС [1].

Сближение Индии и Китая начало прослеживаться с конца 1980-х годов. Главным импульсом для восстановления отношений между странами стал визит премьерминистра Индии Раджива Ганди в КНР в 1988 году [13].

Периодически проводились встречи между главами правительств Китая и Индии, а также ответственными лицами обеих стран. Они смогли договориться о расширении перечня направлений двустороннего сотрудничества. Создали рабочую группу и предприняли ряд действий для решения приграничного конфликта. Договорились о взаимодействии в области пограничного сотрудничества.

В сентябре 1993 года во время официального визита премьер-министра Индии Нарасимхи Рао в Китай было подписано «Соглашение о поддержании мира и спокойствия в пограничных районах вдоль линии фактического контроля» [9].

В том же году Индию с ответным визитом посетил Председатель КНР Цзян Цзэминь, было подписано «Соглашение о создании мер доверия в военной области на линии фактического контроля в районах китайскоиндийской границы». Данные документы стали основой для поддержания стабильности на приграничных территориях, а также мира между двумя странами [4].
Несмотря на ряд принятых мер, развитие добрососедских отношений между Индией и Китаем было приостановлено в связи с проведением Индией испытаний ядерного оружия в 1998 году.

На заявление индийского правительства о том, что поводом для проведения атомных взрывов стала политика Китая в отношении Индии, последний заявил дипломатический протест. После этого выпада индийского правительства индийско-китайские отношения стали налаживаться только спустя три года. Именно тогда, в январе 2002 года, премьер Госсовета КНР Чжу Жунцзи посетил с официальным визитом Индию [6].

В июне 2003 г. КНР и Индия назначили представителей для обсуждения путей выхода из приграничного конфликта. В группу по урегулированию конфликта вошли заместитель министра иностранных дел Китая Дай Бинго и советник по национальной безопасности Индии М.К. Нараянан. После напряженных переговоров они достигли некоторого взаимопонимания в данном вопросе [18].

В 2005 г. с официальным визитом Дели посетил премьер Государственного Совета Китайской Народной Республики Вэнь Цзябао. В результате переговоров между странами были установлены так называемые «отношения стратегического партнерства». В подписанном по итогам переговоров «Соглашении о руководящих политических принципах решения пограничного вопроса», отмечалось, что существующие пограничные споры не должны оказывать влияния на двусторонние отношения. Более того: Китай признал, что гималайское княжество Сикким, оккупированное Индией в 1975 г., является частью индийской территории. А Дели признало Тибет неотъемлемой частью Китая [16].

В 2008 г. индийский премьер-министр Манмохан Сингх нанес ответный визит в Китай, был подписан документ «Совместное видение XXI века КНР и Индийской республикой» [8].

В 2010 г. состоялся очередной визит в Индию премьера Госсовета КНР Вэнь Цзябао, который выдвинул тезис: «В мире достаточно пространства для совместного развития Китая и Индии». В своем Выступлении он отметил, что только политика открытости и совмещения приведет государство к могуществу. Что на планете достаточно пространства для совместного развития Китая и Индии и достаточно областей для сотрудничества между двумя странами. «Мы считаем, что независимость, самостоятельность и неуклонное стремление вперед - это душа одной нации», - сказал китайский руководитель.

Во время визита Вэнь Цзябао в Индию стороны подписали 12 двусторонних соглашений. Принятая совместная декларация провозгласила «стратегическое партнерство» двух государств. Индия заявила, что считает Тибет 
неотъемлемой частью территории КНР, Китай обещал не оспаривать индийскую принадлежность Сиккима. Пекин одобрил намерение Индии добиваться постоянного членства в Совете Безопасности ООН. Рассчитанная на пять лет программа двустороннего торгово-экономического и научно-технического сотрудничества предусматривала увеличение к 2010 году товарооборота между двумя до 30 млрд. долларов, а к 2015 году планировалось создать зоны свободной торговли и устранить таможенные барьеры [12].

Эти дипломатические договоренности позволяют Индии и Китаю наладить экономическое, политическое и культурное сотрудничество и на неопределенный срок отложить решение приграничной проблемы. Регулярными стали встречи глав государств и правительств обеих стран, ежегодными - министров иностранных дел.

17 января 2012 г. был создан «Консультативно-координационный механизм по делам китайско-индийских пограничных территорий», внесший большой вклад в укрепление двусторонних контактов и урегулирование пограничного спора. Во время визита главы правительства Индии М. Сингха в КНР в 2013 году было подписано «Межправительственное соглашение о сотрудничестве по охране границы» [10].

В сентябре 2014 г. состоялся визит председателя КНР Си Цзиньпина в Дели. Он отметил, что Китай и Индия являются важными соседями друг для друга, это крупные развивающиеся страны с формирующимися рынками, они являются двумя важными силами в процессе создания многополярного миропорядка. Обе страны находятся в великом историческом процессе национального возрождения. По мнению международного сообщества, 21-й век принадлежит Азии, а развитие Китая и Индии носит ключевой характер. Гармоничное сосуществование, мирное развитие, сотрудничество и развитие "китайского дракона" и "индийского слона" принесут пользу народам двух стран, население которых составляет 2,5 млрд. человек, а также большому числу развивающихся стран и окажут глубокое влияние на регион и весь мир. Китай рассматривает Индию в качестве долгосрочного стратегического партнера. И надеется вместе с Индией создать более тесные партнерские отношения и углубить сотрудничество на двустороннем, региональном и международном уровнях. «Мы, как лидеры двух стран, должны нести эту историческую обязанность и ответственность», - сказал Си Цзиньпин.

В ходе визита лидеры обсуждали идею транспортного коридора Бангладеш-Китай-Индия-Мьянма, а также другие инфраструктурные проекты, способствующие устойчивому и сбалансированному развитию всех стран региона. Был подписан ряд соглашений, в том числе и в торгово-экономической сфере. Всего было заключено 12 соглашений по экономическим вопросам. Большое внимание в них было уделено сфере транспортных коммуникаций - совместном создании сети скоростных железных дорог [14].

Несмотря на этот явный прогресс, пограничные споры время от времени проявляются. В 2013 и 2014 гг. произошло 2 инцидента в западном приграничном секторе. В период с 2011 по 2014 год количество мелких нарушений Китаем спорной границы между двумя странами увеличилось с 213 до 400. В настоящее время мелкие нарушения, а также более крупные инциденты не прекращаются [7].

В 2017 г. Китай для доказательства того, что не боится решительных действий, перебросил на север Тибета десятки тысяч тонн военных грузов и провел там военные учения с боевыми стрельбами [2].

Определение границы до сих пор не было проведено, то есть стороны продолжают патрулирование в спорных районах, и это провоцирует инциденты. Даже, если демаркация будет произведена, такой договор будет необходимо утвердить в индийском парламенте, согласовать с Политбюро ЦК КПК, в котором существуют различные мнения по вопросу территориальной принадлежности спорных районов. Поэтому в ближайшее время подписание такого соглашения невозможно.

Происходящие инциденты вряд ли смогут трансформироваться в серьезный конфликт, так как существует серьезная экономическая взаимозависимость Индии и Китая. Кроме того, страны разработали консультативнокоординационный механизм по разрешению споров на пограничных территориях.

Китай и Индия тесно сотрудничают в торгово-экономической сфере. Обладая крупнейшими в мире развивающимися рынками и наибольшим населением, две страны заинтересованы во взаимодействии, а не в конфликте друг с другом.

Китай является важнейшим торговым партнером Индии. И его опыт в экономической сфере важен для индийской экономики. Сотрудничество Индии и Китая прослеживается в обрабатывающей промышленности. Ведется активная совместная работа, основанная на опыте Китая в реализации сложных проектов, при строительстве высокоскоростной железной дороги между Дели и Ченнаи. Осуществляется приток китайского капитала в экономику Индии. Китайская и индийская экономики дополняют друг друга, и их сотрудничество будет только расти [17].

В то же время в Индии нарушен баланс спроса и предложения в отношении товаров из Китая. Объем экспорта индийских товаров в КНР значительно ниже, чем объем импорта из Китая. В 2014 г. Индия получила гарантии на инвестиции Китая в размере 20 млрд. долларов в течение следующих 5 лет. Эти средства были использованы 
для улучшения индийской инфраструктуры. Китай предпочитает вкладывать свои капиталы в те сектора индийской экономики, которые наиболее перспективны [17].

В то же время, некоторые военные специалисты из Индии опасаются, что КНР может использовать строящиеся железные дороги в военных целях. Если железные дороги двух стран соединятся в Гималаях, то, в случае начала войны, благодаря им китайская армия сможет быстро продвинуться вглубь Индии. Эта точка зрения сильно осложняет принятие решения о строительстве железной дороги, соединяющей Индию и Китай.

Чтобы укрепить двусторонние отношения и не допустить взаимного охлаждения в будущем, Индия и Китай должны всемерно укреплять контакты и наладить дополнительные механизмы разрешения возможных разногласий. Проводить консультации по совместному развитию. Тесно взаимодействовать в политической, экономической и социально-гуманитарной областях.

Цели внешней политики Китая и Индии практически одинаковы. Она направлена на преодоление мирового экономического кризиса, энергетическую безопасность, иранский и сирийский вопросы, борьбу с терроризмом и т.д. В этих сферах существует практически полное взаимопонимание.

Дели и Пекин выступают за многополярность в международных отношениях и против того, что США пытаются позиционировать себя, как мирового лидера.

В то же время, если на мировом уровне у Индии и Китая споров нет, то на региональном уровне ситуация более сложная. Индия сопротивляется желанию КНР установить свое верховенство в Азии. Несмотря на то, что Китай учитывает интересы Индии, его правительство уверенно работает над тем, чтобы страна стала региональным лидером.

Оставляет желать лучшего ситуация в области гуманитарного и культурного сотрудничества между государствами. Не достаточен объем туристических и культурных обменов. Это помогло бы создать благоприятный климат для гармоничного сосуществования и взаимного уважения. Первое китайско-индийское соглашение по культурному сотрудничеству было подписано 28 мая 1988 г. Однако, в 1990-е годы культурно-гуманитарное сотрудничество между Китаем и Индией практически не реализовывалось.

В мае 1994 г. в Пекине прошел первый индийскокультурный фестиваль, где присутствовало 140 индийских представителей в составе 10 делегаций [18].

Чтобы облегчить гражданам обеих стран процедуру пересечения государственной границы, создаются более благоприятные условия при получении виз. Тем са- мым, увеличивая их количество. Следовательно, растет объем туристических перевозок. Однако ситуация все еще далека от идеала.

Большое внимание общественности двух стран привлекают регулярные взаимные визиты глав Индии и Китая, которые способствуют расширению разнообразных связей. Но не уменьшается потребность в расширении культурных и туристических контактов, а также в образовательных студенческих обменах. Периодически проводятся выставки, посвященные культуре и истории обеих стран.

Китайские ученые детально изучают индийскую культуру и религию. Историю появления буддизма в Северной Индии и его дальнейшее распространение по Азии, в том числе по Китаю. Ведь именно буддизм является наиболее широким и прочным мостом, связывающим китайскую и индийскую культуры.

Обе стороны пытаются увеличить поток туристов. Индийское руководство рассматривает поездки своих граждан в Китай не просто как туристические туры, а как часть гражданской неофициальной дипломатии. Индийские туристы рассматриваются в качестве распространителей культуры сопредельной страны. Схожую позицию занимает и правительство КНР [18].

В сентябре 2003 г. в университете Дели прошел китайско-индийский культурный фестиваль.

Налаживается сотрудничество в сфере здравоохранения. 9 января 2008 г. в Пекине была открыта Совместная китайско-индийская медицинская миссия, направленная на проведение бесплатных консультаций и раздачу лекарств населению сельских районов Индии и Китая. Инициатором ее появления стал председатель Китайской народной ассоциации дружбы с иностранными государствами Чэнь Хаосу [15].

Количество студентов-медиков из Индии, проходящих обучение или стажировки в китайских университетах и колледжах, неуклонно растет. «С 2004 г. более чем 20 китайских университетов начали усиленно набирать студентов из Индии, так что для сотен целеустремленных индийских докторов, неспособных или не имеющих возможностей получить место в медицинских колледжах дома, Китай стал Меккой», - писала индийская газета «Хинду» [15].

Китайцы интересуются индийской культурой, танцевальным искусством, кулинарией. В Пекине открывается все больше ресторанов индийской кухни, в которых китайцы составляют до 70\% клиентуры.

Средства массовой информации Китая обращают большое внимание на культурную жизнь Индии. Искусство способствует духовному сближению народов. 
Таким же средством является и спорт. Китайская пресса довольно подробно освещала успехи индийских спортсменов во время Олимпийских игр в Пекине.

Межгосударственная молодежная политика является приоритетным направлением в деятельности дипломатических миссий обеих стран, так как большинство населения составляет молодежь. Именно им предстоит определять политику и экономическое развитие стран в скором времени.

Во время визита премьера Государственного Совета КНР Вэнь Цзябао в Индию в 2005 г. стороны договорились об осуществлении молодежных обменов. Первой посетила соседнюю страну делегация Индии. Это произошло в октябре 2006 года. Ответный визит китайской делегации состоялся месяцем позже. Встреча была организована на самом высоком уровне. Учитывая положительные результаты работы первых делегаций, было принято решение увеличить численность молодых людей, принимающих участие в обмене. В последующих делегациях участвовало более 500 человек [15].
Но учитывая численность населения Индии и Китая, количество молодых людей по обмену катастрофически мало. Но это наиболее талантливая и перспективная молодежь, формирующая политическую, экономическую, научную, культурную и спортивную элиту обеих стран.

Таким образом, можно сказать, что международное культурное сотрудничество Индии и Китая в целом отражает весь сложный спектр политических взаимоотношений этих стран. Взаимное недоверие не располагает к расширению контактов в других областях. Партнерские отношения Индии и Китая носят довольно сложный характер. Правительства, равно как и население обеих стран, в целом настороженно относятся друг к другу. Индия не является основным партнером Китая в проектах «Один пояс - один путь», скорее, они проходят ее лишь по касательной. Поэтому правительство КНР далеко не так интенсивно, как могло бы, проводит свою политику, направленную на строительство долгосрочных отношений с Индией.

\section{ЛИТЕРАТУРА}

1. Белокреницкий В.Я. Стратегический треугольник Россия - Китай - Индия: реальность конфигурации // Китай в мировой политике. М., 2001.

2. Военные новости: новая китайско-индийская война? 20.07.2017 // https://inosmi.ru/politic/20170720/239860244.html (Дата 0бращения 18.05.2012)

3. Вэнь Цзябао: В мире достаточно пространства для совместного развития Китая и Индии и достаточно областей для проведения сотрудничества между двумя странами. 17.12.2010 // http://russian.people.com.cn/31520/7233868.html (Дата обращения 11.05.2021)

4. Геостратегическая политика Китая // http://geolike.ru/page/gl_2792.htm (Дата обращения 08.04.2021)

5. Дела соседские // Военное обозрение. 26 декабря 2012. https://topwar.ru/22332-dela-sosedskie.html (Дата обращения 08.04.2012)

6. Дударёнок А.С. Проблема территориально-пограничного спора в современных индийско-китайских отношениях // Журнал международного права и международных отношений. 2005. № 4. Электронная версия - http://evolutio.info/content/view/801/113/ (Дата обращения 10.05.2021)

7. Индийско-китайский пограничный конфликт. 03.11.2014 // http://inosmi.ru/world/20141103/224052245.html (Дата обращения 12.05.2012)

8. иитай и Индия: совместное моделирование миросистемы XXI века. 19.01.2008 // http://www.fondsk.ru/news/2008/01/19/8598-8598.html (Дата 0бращения 10.05.2021)

9. Китай и Индия на пороге формирования нового типа отношений // Лента: Политика. 24.05.2013 http://www.rodon.org/polit-130524110108 (Дата 06 ращения 08.05.2021)

10. Китай и Индия подписали Соглашение о создании консультативно-координационного механизма по делам китайско-индийских пограничных территорий. 18.01.2012 // http://russian.people.com.cn/31520/7708343.html (Дата обращения 11.05.2021)

11. Кузнецов В.С. Китай - Индия: новые акценты и реалии // Китай в мировой и региональной политике (история и современность). М., 2003.

12. Лузянин С., Сафронова Е., Свешников А. Некоторые итоги внешнеполитической активности КНР в 2005 году // Проблемы Дальнего Востока. № 3.2006.

13. Педин А.В. Китайско-индийские отношения на современном этапе // Китайская традиционная культура и проблемы модернизации. Тезисы V международной научной конференции «Китай, китайская цивилизация и мир. История, современность, перспективы». М. 1994.

14. Председатель КНР Си Цзиньпин и премьер-министр Индии Н.Д. Моди договорились строить более тесные партнерские 0тношения. 18.09 .2014 // http:// russian.news.cn/china/2014-09/18/c_133653843.htm (Дата обращения 12.05.2021)

15. Степанова Е.Н. Китай и Индия: традиции и новации служат взаимопониманию // http://www.synologia.ru/a/Китай_-_Индия (Дата обращения 18.04.2021)

16. Чэнь Чжихао. Китай и Индия: отношения, вызовы, перспективы // Информационно-аналитический портал Геополитика http://www.geopolitica.ru/article/ kitay-i-indiya-otnosheniya-vyzovy-perspektivy\#.V-FOVNSLSt8 (Дата обращения 10.05.2021)

17. Чэнь Чжихао. Китайско-индийские отношения конца XX - начала XXI вв.(1988-2014 гг.). Автореферат канд. дисс. М., 2015. China - India. Beijing, 2003.

18. Indo-Chinese declaration New Delhi, June 242005 // The Tribune. 2003, № 25. http://www.tribuneindia.com/2003/20030625/main9.htm (Дата обращения 10.05.2021)

() Гао Вэньцзин (gaowenjing777@hotmail.com).

Журнал «Современная наука: актуальные проблемы теории и практики» 